\title{
Bolsas de Estudo no Brasil: uma modalidade de fomento FAPESP à pesquisa em Comunicação
}

\author{
Scholarships in Brazil: a FAPESP's modality promotion to Communication research \\ Becas de Estudio en Brasil: una modalidad de Fomento FAPESP a la investigación en \\ Comunicación
}

DOI: https://doi.org/10.1590/1809-5844202016

\section{Rodrigo Gabrioti ${ }^{1}$}

https://orcid.org/0000-0001-6745-3600

${ }^{1}$ (Escola Superior de Administração, Marketing e Comunicação, Curso de Jornalismo. Sorocaba - SP, Brasil).

\section{Resumo}

O objetivo deste trabalho é apresentar parte dos resultados obtidos em nossa tese de Doutorado que pesquisou a legitimação, a contribuição e a construção da Área da Comunicação no contexto das pesquisas apoiadas pela Fundação de Amparo à Pesquisa do Estado de São Paulo (FAPESP). Trazemos aqui as perspectivas e tendências apontadas, a partir de 583 Bolsas de Estudo no Brasil, uma das modalidades de fomento que viabiliza estudos de Iniciação Científica, Mestrado, Doutorado, Doutorado Direto e Pós-Doutorado. Tal cenário é apresentado com base em estratégias multimetodológicas, sendo as mais representativas a Pesquisa Bibliográfica, a Pesquisa Documental e a Análise de Conteúdo. Conclui-se que em 25 anos analisados (1992-2016), a Área segue sendo atrativa a novos pesquisadores e que o fluxo de produção nos permite dizer que os beneficiários produzem conhecimento para a Área, validado pelo corpo técnico-científico da Fundação.

Palavras-chave: Bolsas de Estudo. Brasil. Comunicação. FAPESP. Fomento.

\begin{abstract}
This paper's goal is to present part of the results obtained in our PhD thesis, which investigated the legitimization, contribution and construction of the Communication Area in the context of research supported by the Foundation for Research Support of the State of São Paulo (FAPESP). We present here the perspectives and tendencies pointed out, from 583 Scholarships in Brazil, one of the modalities of fomentation that makes feasible studies of Scientific Initiation, Masters, Doctorate, Direct Doctorate and Postdoctoral. This scenario is presented based on multi-methodological strategies, the most representative being Bibliographic Research, Documentary Research and Content Analysis. It is concluded that in 25 years analyzed (1992-2016), the Area continues to be
\end{abstract}


attractive to new researchers and that the production flow allows us to say that the beneficiaries produce knowledge for the Area, validated by the technical-scientific body of the Foundation.

Keywords: Scholarships. Brazil. Communication. FAPESP. Support.

\section{Resumen}

El propósito de este artículo es presentar parte de los resultados alcanzados en nuestra tesis de Doctorado que ha investigado la legitimación, contribución y construcción del Área de la Comunicación en el contexto de las investigaciones apoyadas por la Fundación de Apoyo a la Investigación del Estado de San Pablo (FAPESP). Hemos traído las perspectivas y tendencias apuntadas, tras 583 Becas de Estudio en Brasil, una de las modalidades de fomento que permite los estudios de Iniciación Científica, Maestría, Doctorado, Doctorado Directo y Pos-Doctorado. El escenario se presenta sobre estratégias multimetodologicas, siendo las más representativas la Investigación Bibliográfica, la Investigación Documental y el Análisis de Contenido. Se concluyó que en 25 años analizados (1992-2016), el Área sigue siendo atractivo a nuevos investigadores y que la producción permite decir que los beneficiários aportan conocimiento al Área, reconocido por el cuerpo técnico-científico de la Fundación.

Palabras-clave: Becas de Estudio. Brasil. Comunicación. FAPESP. Promoción.

\section{Breve panorama}

A discussão sobre a produção de pesquisas, por meio de Bolsas de Estudo no Brasil, envolvendo pesquisadores de Iniciação Científica, Mestrado, Doutorado, Doutorado Direto e Pós-Doutorado, que conseguiram o fomento da Fundação de Amparo à Pesquisa do Estado de São Paulo (FAPESP), entre os anos de 1992 e 2016, é o mote deste artigo que apresenta parte de resultados obtidos pela pesquisa de nossa tese de Doutorado (GABRIOTI, 2018), realizada junto ao Programa de Pós-Graduação em Comunicação, da Universidade Metodista de São Paulo, sob a orientação do saudoso professor José Marques de Melo .

Inicialmente, é necessário abordar o percurso de pesquisa que envolve estratégias multimetodológicas, com destaque para as revisões bibliográficas e a Pesquisa Documental, a partir dos resumos de projetos cadastrados na Biblioteca Virtual da FAPESP², para aspectos quantitativos; e a Análise de Conteúdo, seguindo os pressupostos de Bardin (2011), para aspectos qualitativos. Gobbi (2015) considera que um dos grandes desafios para compreender o cenário comunicativo brasileiro, por meio da academia, é conhecer e reconhecer os temas que cotidianamente provocam pesquisadores. Imbuídos dessa perspectiva, esmiuçamos pelo cenário da FAPESP, dados como pesquisadores responsáveis, instituições, palavras-chave, entre outros, registrados na base de dados em um recorte específico de tempo que vai de 1992,

1 Nasceu em Palmeira dos Índios (AL), em 15 jun. 1943, e morreu, em São Paulo, em 20 jun. 2018.

2 Centro de Documentação e Informação, armazena dados sobre projetos que conseguiram fomento nas mais diversas modalidades. O Relatório de Atividades 2016 da FAPESP revelou que a Biblioteca Virtual conta, entre 1992 e 2016, com 118.583 Bolsas no Brasil; 9.392 Bolsas no Exterior e 90.393 Auxílios à Pesquisa cadastrados. Acesso à Biblioteca Virtual em www.fapesp.br/bv. 
o primeiro ano de pesquisas registradas no sistema, até 2016, o último ano de financiamento a pesquisas que seriam concluídas antes do encerramento do nosso Doutorado, no primeiro semestre de $2018^{3}$.

Assim se totalizam 25 anos, sobre os quais foi possível mapear os estudos que representam momentuns de investigação, ou seja, pesquisas apoiadas nas mais diversas modalidades que apresentam contribuições e indícios ao que se tem produzido na Área. Esse período analisado sinaliza tendências da Comunicação, expõe relações acadêmicas instituídas, demonstra procedimentos de trabalho adotados nas mais diversas possibilidades acadêmicas e desperta o interesse de pesquisadores, desde as novas gerações até as mais experientes, com alguns sendo referências seminais para pensar, discutir e teorizar a Área.

Ao apresentarmos as Bolsas de Estudo no Brasil, tratamos de 583 pesquisas entre 912 projetos que atendem a nossa pergunta de pesquisa: independentemente do impasse conceitual experimentado e mal resolvido da Comunicação, quando se considera toda essa amostra detalhada, quais tendências e perspectivas podem ser atribuídas à construção da natureza taxionômica dos estudos em Comunicação?

Essa sistematização do conhecimento produzido se dá graças aos sujeitos de pesquisa, validado sob dois marcos teóricos, um de Bachelard (1996) e outro de Dilthey (2010). No conceito de espírito científico, Bachelard (1996) nota na aplicabilidade da pesquisa uma inflexão, a qual fazemos pelas investigações realizadas com apoio da FAPESP. Um processo bastante longo para uma plausível e tão jovem ciência no auge de sua meia idade e que experimenta sua primeira passagem secular cujo sentido de construção leva, como o próprio Bachelard (1996) estabelece, ao Conhecimento Aproximado como equação diferencial do movimento epistemológico.

As contribuições de Dilthey (2010) sinalizam para uma realidade que confere certo grau de materialidade aos pesquisadores que compreendem e interpretam fenômenos na construção de conceitos e juízos em um processo histórico e social que revê as condições vivenciadas em espaços e tempos que propiciam um conjunto significante defrontado e apreendido pela condição espiritual do pesquisador cujas particularidades e compreensões reconstroem as vivências, sob a perspectiva do presente, atribuindo ao conhecimento construído uma significação de experiências para a formulação de conceitos. Às empirias, os pesquisadores atribuem sentido a um problema e o questionam, assim construindo e validando o espírito científico, que não se caracteriza por uma opinião formada sobre o que não se conhece (BACHELARD, 1996). Para Bachelard (1996), sem pergunta não há conhecimento. E o pesquisador que se conforma com as respostas obtidas tem seu espírito científico cessado em crescimento.

3 O ano de 2017 foi desconsiderado para que não houvesse nenhuma pesquisa em andamento. 


\section{Ciência: do exercício ao financiamento}

Na FAPESP, todo fomento deriva do dinheiro público. Analisados os anos de 2016 e 2017, o investimento nas Bolsas do Brasil foi de R\$ 69.933.056,14 (6,48\%). Em 2016, apenas para Bolsas no Brasil, foram investidos R\$ 85.267.060,09. A quantia pode ser vista como elevada, se considerada sua evolução histórica nesta década 2011-2020, marcada por redução de investimentos no Brasil, cuja crise política e financeira colocou em xeque a ciência com cortes de bolsas, atrasos de repasses, laboratórios sucateados e pesquisadores de mãos atadas por falta de verbas.

Segundo a Profa. Dra. Esther Império Hamburger ${ }^{4}$, a FAPESP pode ser considerada um modelo de gestão já que, na década de 1950, visionários inseriram na constituição paulista que as pesquisas deveriam ser viabilizadas com dinheiro da arrecadação estadual. Hamburger (2017) ressalta que a Fundação não está alheia aos acontecimentos do mundo e que embora a crise econômica do Brasil tenha encolhido a arrecadação, a FAPESP não perde sua credibilidade com investimentos assumidos. Mas se a receita cai, o repasse consequentemente se torna menor. O diagnóstico disto é um choque entre Ciência e Gestão que indispensavelmente relaciona decisões administrativas com decisões científicas.

Essa diminuição torna o trabalho de quem está decidindo muito penoso porque assim você vê que as pessoas têm acesso em geral, recebe bem as críticas que os pareceristas fazem, né, e refazem seus projetos. Então eles vão melhorando. E as pessoas, enfim, com essa onda de publicação, cobrança de produtivismo... estão produzindo, estão publicando muito. Isso eu acho que não é só na nossa Área. É em geral. O nível está melhorando muito. Só que as Áreas têm mais ou menos bolsas com a proporção de pedidos (HAMBURGER, 2017).

Os trabalhos aprovados recebem uma quantia para o desenvolvimento da investigação, porém, não conseguimos assimilar que os problemas de pesquisa estejam condicionados diretamente a esta questão. Cremos que, ao buscar o fomento, o pesquisador quer o financiamento de seu trabalho, sendo que o retorno da FAPESP se encontra no incentivo e aval de cientificidade ao conhecimento. A supervisão pública que consta da relação entre FAPESP e pesquisador como espécie de contrato em nome do conhecimento científico existe para sustentar a transparência de todo o processo. Fica evidente que os interesses são estritamente diferentes.

Sem dados específicos dentro da organização da FAPESP, a Comunicação se incorpora ao conjunto de saberes das Ciências Humanas e Sociais, que, como Área, se posicionou na quinta colocação nos investimentos da instituição em $2016^{5}$ e chegou ao segundo lugar em

4 Coordenadora da Área CHS II da FAPESP em entrevista concedida ao autor em 10 out. 2017.

5 Até o fechamento da tese, o último Relatório divulgado pela FAPESP foi o de 2016. 
contratação de bolsas com investimento da ordem de R 80 milhões no cenário nacional nesse mesmo ano. São evidências de como ainda pouco se investe na Área, característica peculiar que fez o professor José Marques de Melo declarar para Moura (2014) o pouco prestígio das pesquisas em Comunicação nessa perspectiva de investimento.

Embora a questão financeira seja de interesse maior da FAPESP, como instituição, aos pesquisadores o interesse está em saber como a Área vem sendo discutida e construída por meio do fomento. Por isso, nosso recorte na amostra geral da tese envolve Bolsas no Brasil (Iniciação Científica, Mestrado, Doutorado, Doutorado Direto e Pós-Doutorado), Bolsas no Exterior (Bolsa Estágio para Iniciação Científica, Bolsa Estágio para Mestrado, Bolsa Estágio para Doutorado, Bolsa Estágio para Pós-Doutorado e Bolsa Pesquisa) e Auxílios à Pesquisa (Auxílios Regulares, Auxílios Publicações e Auxílios Pesquisador Visitante).

A construção das amostras se deu pelos dados coletados da Biblioteca Virtual considerando a concepção de Campos e Gomes (2007), os quais identificam o problema que a Taxonomia tenta responder e o volume de informação agregada. Assim, nosso problema é identificar o que foi produzido com fomento e o volume agregado são as amostras e resultados decorrentes de Bolsas de Estudo no Brasil.

Para atingir este objetivo, foram cumpridas quatro etapas. Pela primeira, Captura do Conhecimento, acessamos a Biblioteca Virtual para identificar os processos de fomento em Comunicação. No segundo momento, Análise dos Documentos e Informações, cada processo foi recuperado e lido para a identificação de elementos de informação. O terceiro passo consistiu na Elaboração da Estrutura Classificatória formulando sete categorias: (1) Instituições: Universidades e Faculdades, públicas e particulares, que aderem ao fomento como recurso de pesquisa; (2) Pesquisadores: homens e mulheres que pesquisam, considerando pesquisadores responsáveis e beneficiários que nem sempre são a mesma pessoa; (3) Temas de Pesquisa: revelados pelas palavras-chave e mencionados como assuntos de pesquisa; (4) Metodologias: quantificação dos tipos a partir dos projetos submetidos; (5) Referências Bibliográficas: autores utilizados como referencial, analisados pela dicotomia da nacionalidade brasileiros versus estrangeiros; (6) Pesquisadores estrangeiros: quem recebeu colegas ou alunos brasileiros em instituições no exterior; e (7) Países-sede: onde pesquisadores realizaram seus trabalhos.

A quarta etapa foi a da Validação, com a aplicação da Análise de Conteúdo, em viés quantitativo para gerar Indicadores e em viés qualitativo para gerar Inferências. Especificamente, neste artigo, o interesse é pelos indicadores gerados pelas Bolsas de Estudo no Brasil.

\section{Cenários quantitativos}

Entre os 912 projetos apoiados, 583 estão vinculados às Bolsas no Brasil. Esse montante representa $63,92 \%$ do total de pesquisas financiadas como demonstra o quadro a seguir. 
Quadro 1 - Bolsas no Brasil

\begin{tabular}{lll}
\hline CATEGORIA & ANOS & QUANTIDADE \\
\hline Iniciação Científica & $1992-2016$ & 299 \\
Mestrado & $1992-2016$ & 178 \\
Doutorado & $1993-2016$ & 68 \\
Doutorado Direto & $2007-2016$ & 2 \\
Pós-Doutorado & $1998-2016$ & 36 \\
\hline
\end{tabular}

Fonte: Biblioteca Virtual FAPESP.

A Iniciação Científica tem 299 projetos financiados, o que representa 51,28\% das pesquisas financiadas. Isto significa mais da metade dos estudos fomentados pela FAPESP. A UNESP Bauru, com a Faculdade de Artes, Arquitetura e Comunicação (FAAC), representa a metade das bolsas (50,83\%). Depois aparecem a USP, com 79 bolsas (26,42\%); Universidade Metodista de São Paulo; e a PUC-SP com 10 bolsas cada (3,35\%). O quadro a seguir demonstra o cenário de distribuição dessas 299 bolsas de estudo.

Quadro 2 - Distribuição das 299 Bolsas em Iniciação Científica

\begin{tabular}{lll}
\hline TIPO DE INSTITUIÇÃO & QUANTIDADE & ÍNDICE PERCENTUAL \\
\hline Universidades Públicas & 250 & $83,61 \%$ \\
Universidades Particulares & 38 & $12.71 \%$ \\
Faculdades & 3 & $1 \%$ \\
Institutos de Pesquisa & 7 & $2,34 \%$ \\
Escola & 1 & $0,34 \%$ \\
\hline
\end{tabular}

Fonte: Biblioteca Virtual FAPESP.

A maior produtividade (63,55\%) está no interior de São Paulo. Entre essas 299 bolsas, 162 pesquisas tiveram orientadores homens (54,18\%), enquanto 137 pesquisas (45,82\%) foram orientadas por mulheres. O professor que mais orientou projetos foi Maximiliano Martin Vicente, da UNESP Bauru, com 26 pesquisas. Considerando todas as bolsas concedidas, 193 pesquisas $(64,55 \%)$ foram realizadas por mulheres e 106 (35,45\%) por homens.

A Iniciação Científica reuniu, entre os anos analisados, 756 temas de pesquisa ${ }^{6}$. O Jornalismo responde por 45 menções (5,95\%); Imprensa com 18 (2,38\%); Cultura e Censura, com 15 menções cada (1,99\%); Relações Públicas e Teatro tiveram 12 cada (1,59\%). Já em relação às Metodologias, estão representados os seguintes recursos:

6 Entre 801 temas, foi extraído um total de 45 temas entre os não informados e aqueles que se confundem com metodologias de pesquisa. 
Quadro 3 - Metodologias na Iniciação Científica

\begin{tabular}{lll}
\hline TIPO DE METODOLOGIA & NÚMERO DE MENÇÕES & ÍNDICE PERCENTUAL \\
\hline Pesquisa Bibliográfica & 29 & $21,32 \%$ \\
Entrevista & 14 & $10,29 \%$ \\
Análise de Conteúdo & 11 & $8,09 \%$ \\
Pesquisa Documental & 9 & $6,62 \%$ \\
Estudo de caso & 7 & $5,15 \%$ \\
Pesquisa Exploratória & 6 & $4,41 \%$ \\
Pesquisa Qualitativa & 6 & $4,41 \%$ \\
Análise do Discurso & 6 & $4,41 \%$ \\
Pesquisa de campo & 6 & $4,41 \%$ \\
Pesquisa Quantitativa & 4 & $2,94 \%$ \\
Pesquisa Teórica & 3 & $2,21 \%$ \\
Pesquisa Descritiva & 3 & $2,21 \%$ \\
\hline
\end{tabular}

Fonte: Biblioteca Virtual FAPESP.

Para saber a respeito das Referências Bibliográficas adotadas em 299 bolsas da Iniciação Científica, precisamos excluir 269 pesquisas que não informaram seus referenciais bibliográficos. Ou seja, em apenas 30 pesquisas, 64 autores são mencionados entre 74 referências bibliográficas. Os números são díspares porque, em muitos casos, apesar de pesquisas diferentes, os autores são citados mais de uma vez.

Quadro 4 - Referências Bibliográficas na Iniciação Científica

\begin{tabular}{lll}
\hline AUTORES & NÚMERO DE PESQUISAS & ÍNDICE PERCENTUAL \\
\hline Umberto Eco & 3 & $4,05 \%$ \\
Mikhail Bakthin & 2 & $2,7 \%$ \\
J. Greimas & 2 & $2,7 \%$ \\
Jürgen Habbermas & 2 & $2,7 \%$ \\
Meyer & 2 & $2,7 \%$ \\
Benedict Andersen & 2 & $2,7 \%$ \\
Charles S. Peirce & 2 & $2,7 \%$ \\
Gilles Deleuze & 2 & $2,7 \%$ \\
\hline
\end{tabular}

Fonte: Biblioteca Virtual FAPESP.

Desses 64 nomes relacionados, 40 são estrangeiros (62,5\%), 19 brasileiros (29,69\%) e cinco $(7,81 \%)$ não tiveram identificada a origem por falta de nome completo nos resumos 
das pesquisas. Como se pode perceber, o número de estrangeiros é mais que o dobro de pesquisadores nacionais utilizados e identificados.

As primeiras impressões da Iniciação Científica são, entre os temas de pesquisa, o predomínio do Jornalismo, que se ramifica em inúmeras modalidades: Jornalismo Científico, Jornalismo Comunitário, Reportagem, Entrevista Jornalística, entre outros. Ato contínuo à influência desse tema, aparecem os estudos de Imprensa. O mesmo ocorre com o tema Comunicação, que se reparte, ao olhar dos pesquisadores, em Pública, Integrada, Visual, Intercultural, em sua Filosofia etc... Percebe-se pouca abordagem em relação ao digital, temática ocupada preponderantemente na atualidade pelas mídias sociais; o Jornalismo; a Mídia e a Cultura. Um sintoma curioso, porque a Iniciação Científica reúne jovens da Graduação, embora isto se justifique pelo largo período em que a Internet teve escala de valorização e integração à vida humana, em especial, com a chegada do século XXI. Enfim, a ramificação da Área é um dos indicadores de sua complexidade, tornando-se decorrência de um conceito-chave maior que em vez de pensar em quantas possibilidades é possível pesquisar a Comunicação, abriga “campos próprios” de conhecimento.

É ainda uma característica notória que esses pesquisadores, em início de formação, fazem parte de projetos maiores, especialmente de seus orientadores, e adotam a Pesquisa Bibliográfica como principal estratégia metodológica, condição plausível neste primeiro contato do jovem pesquisador com o conhecimento.

\section{Bolsas de Mestrado (1992-2016)}

Entre as 583 bolsas concedidas, 178 foram para Mestrado, o que representa 30,53\% dos fomentos. A maior concentração está na USP, cuja maioria foi conseguida por pesquisadores em formação da Escola de Comunicações e Artes (ECA), com 65 bolsas, o equivalente a 36,51\% dos fomentos conseguidos na instituição. Na iniciativa privada, a PUC-SP lidera com 16 bolsas, o correspondente a 8,98\% dos benefícios da FAPESP.

Dessas 178 bolsas, 171 foram concedidas para Universidades (96,06\%) e apenas sete para faculdades (3,94\%). Quando olhamos os dados de universidades, estabelecemos a diferenciação numérica entre o que é fornecido para as públicas e as particulares. Assim, precisamos considerar como base um total de 171 que se subdivide em 145 financiamentos para universidades públicas (84,8\%) e 26 para universidades particulares (15,2\%). Os quadros seguintes demostram essa repartição.

Quadro 5 - Distribuição das 145 Bolsas de Mestrado a Universidades Públicas

\begin{tabular}{lll}
\hline INSTITUIÇÃO & NÚMERO DE BOLSAS & ÍNDICE PERCENTUAL \\
\hline USP & 71 & $48,97 \%$ \\
UNESP & 41 & $28,28 \%$ \\
UNICAMP & 22 & $15,18 \%$
\end{tabular}




\begin{tabular}{lll}
\hline INSTITUIÇÃO & NÚMERO DE BOLSAS & ÍNDICE PERCENTUAL \\
\hline UFSCAR & 10 & $6,89 \%$ \\
UFABC & 1 & $0,68 \%$ \\
\hline
\end{tabular}

Fonte: Biblioteca Virtual FAPESP.

Quadro 6 - Distribuição das 26 Bolsas de Mestrado a Universidades Particulares

\begin{tabular}{lll}
\hline INSTITUIÇÃO & NÚMERO DE BOLSAS & ÍNDICE PERCENTUAL \\
\hline PUC-SP & 16 & $61,54 \%$ \\
METODISTA S.PAULO & 3 & $11,54 \%$ \\
UNIP & 3 & $11,54 \%$ \\
USCS & 3 & $11,54 \%$ \\
UNISO & 1 & $3,84 \%$ \\
\hline
\end{tabular}

Fonte: Biblioteca Virtual FAPESP.

Quadro 7 - Distribuição das sete Bolsas de Mestrado a Faculdades Particulares

\begin{tabular}{lll}
\hline INSTITUIÇÃO & NÚMERO DE BOLSAS & ÍNDICE PERCENTUAL \\
\hline CÁSPER LÍBERO & 4 & $57,15 \%$ \\
ESPM & 3 & $42,85 \%$ \\
\hline
\end{tabular}

Fonte: Biblioteca Virtual FAPESP.

O maior número de bolsas foi concedido à Capital, mas, o interior e o ABC Paulista também aparecem nas estatísticas.

Quadro 8 - Localidade das Pesquisas com Bolsas de Mestrado no Estado

\begin{tabular}{lll}
\hline LOCALIZAÇÃO GEOGRÁFICA & NÚMERO DE BOLSAS & ÍNDICE PERCENTUAL \\
\hline S.PAULO - CAPITAL & 97 & $54,50 \%$ \\
S.PAULO - INTERIOR & 74 & $41,57 \%$ \\
GRANDE SP (ABC) & 7 & $3,93 \%$ \\
\hline
\end{tabular}

Fonte: Biblioteca Virtual FAPESP.

Todas essas bolsas tiveram, como orientadores, 93 homens (52,24\%) e 85 mulheres (47,76\%). Assim como na Iniciação Científica, o professor que mais orientou, no Mestrado, foi Maximiliano Martin Vicente, com 10 projetos. Em relação aos orientandos, as mulheres predominam: são 115 (64,61\%) diante de 63 homens (35,39\%). 
Passando aos temas de pesquisa, o levantamento inicial apontou 440 temas, porém, destes precisamos excluir 59 pesquisas que não informaram seus temas, junto a outras que confundem metodologias com temas de pesquisa. Essa confusão é recorrente nesse quesito. Assim, o real número é de 381 temas sobre os quais serão representadas as amostras superiores a $2 \%$. Os indicadores nos mostram temáticas bastante superficiais, ou seja, a diversidade se confirma como variável influenciadora na formação da Área.

Quadro 9 - Temas de Pesquisa no Mestrado

\begin{tabular}{lll}
\hline TEMAS & NÚMERO DE MENÇÕES & ÍNDICE PERCENTUAL \\
\hline Jornalismo & 18 & $4,72 \%$ \\
Internet & 11 & $2,88 \%$ \\
Linguagem & 10 & $2,62 \%$ \\
Tecnologia & 9 & $2,36 \%$ \\
\hline
\end{tabular}

Fonte: Biblioteca Virtual FAPESP.

Sobre metodologia, das 178 pesquisas, 97 (54,5\%) não trazem essa informação. Logo, há 81 pesquisas (45,50\%) que informaram as metodologias, totalizando 127 citações. As metodologias mais representativas superaram o índice de 5\% na amostragem.

Quadro 10 - Metodologias de Pesquisa no Mestrado

\begin{tabular}{lll}
\hline TIPO DE METODOLOGIA & NÚMERO DE MENÇÕES & ÍNDICE PERCENTUAL \\
\hline Estudo de Caso & 14 & $11,02 \%$ \\
Pesquisa Bibliográfica & 13 & $10,23 \%$ \\
Pesquisa Qualitativa & 9 & $7,08 \%$ \\
Pesquisa Documental & 7 & $5,51 \%$ \\
Análise do Discurso & 7 & $5,51 \%$ \\
\hline
\end{tabular}

Fonte: Biblioteca Virtual FAPESP.

Quando se analisa a Bibliografia, nota-se um expressivo número de pesquisas que não informaram esse dado. Das 178 bolsas, 146 (82,02\%) deixaram de fazer isso. As informações sobre bibliografia estão em apenas 32 pesquisas (17,98\%), com os autores sendo referenciados 103 vezes e usados em mais de uma pesquisa. O quadro que segue traz os autores que superaram 1,5\% de representatividade. Nele, timidamente se vê as literaturas brasileira e latino-americana presentes. Isto se justifica, possivelmente, pelo uso dos textos da professora Lúcia Santaella nas investigações de seus orientandos, que dão à PUC uma boa performance de pesquisas nesta modalidade, e também pela presença de um pensador com grande trânsito na pesquisa brasileira em Comunicação: Jesús Martín-Barbero. 
Quadro 11 - Autores mais citados nas Pesquisas de Mestrado

\begin{tabular}{lll}
\hline AUTOR & NÚMERO DE PESQUISAS & ÍNDICE PERCENTUAL \\
\hline Lúcia Santaella & 3 & $2,91 \%$ \\
Jacques Lacan & 3 & $2,91 \%$ \\
Mikhail Bakthin & 3 & $2,91 \%$ \\
Manuel Castells & 2 & $1,94 \%$ \\
Maurizio Lazzarato & 2 & $1,94 \%$ \\
Boaventura de Souza Santos & 2 & $1,94 \%$ \\
Christine Greiner & 2 & $1,94 \%$ \\
Jesús Martin-Barbero & 2 & $1,94 \%$ \\
Michel Foucault & 2 & $1,94 \%$ \\
Marshall McLuhan & 2 & $1,94 \%$ \\
Erving Goffman & 2 & $1,94 \%$ \\
J.Greimas & 2 & $1,94 \%$ \\
Dominique Wolton & 2 & $1,94 \%$ \\
Pierre Lévy & 2 & $1,94 \%$ \\
Harry Pross & 2 & $1,94 \%$ \\
Helena Katz & 2 & $1,94 \%$ \\
\hline
\end{tabular}

Fonte: Biblioteca Virtual FAPESP.

Entre 83 autores mencionados, nota-se, mais uma vez, o predomínio da literatura estrangeira na Área.

Quadro 12 - Nacionalidade dos autores referenciados em Mestrado

\begin{tabular}{lll}
\hline NACIONALIDADE & AUTORES & ÍNDICE PERCENTUAL \\
\hline Estrangeiros & 70 & $84,34 \%$ \\
Brasileiros & 10 & $12,05 \%$ \\
Não identificada & 3 & $3,61 \%$ \\
\hline
\end{tabular}

Fonte: Biblioteca Virtual FAPESP.

Quando trazemos os dados de referências bibliográficas e suas nacionalidades, a pesquisadora brasileira Lúcia Santaella aparece como uma das mais citadas. Sobre o predomínio da literatura estrangeira em nossa Área, ela disse ${ }^{7}$ que isto tem relação com a História, afinal, as universidades foram criadas a partir do século XI e, desde então, os pensadores europeus vieram trabalhando por tantos séculos. No Brasil, as universidades datam do século XX,

7 Entrevista concedida ao autor por e-mail em 3 out.2017. 
tanto que ela recorda do início institucional da Comunicação, nos anos 1970. Por isso, esse caráter recentíssimo é a justificativa dada pela pesquisadora à condição exposta. Santaella (2017) destaca que "nossas escolhas têm de ser guiadas pela qualidade da informação que buscamos e que encontramos e não pela nacionalidade dos autores. Um grande pensador não tem nacionalidade. Ele pertence à espécie dos seres pensantes e não a um país”.

Como impressões primeiras das bolsas de Mestrado, repete-se a questão da fragmentação temática, tratada na Iniciação Científica. Quando olhamos para a metodologia, vê-se equilíbrio entre Estudo de Caso e Pesquisa Bibliográfica, o que sinaliza para estudos pontuais nessa fase de formação do pesquisador. Entre os temas, o Jornalismo continua predominando, mas já se verifica a presença de estudos sobre novas práticas, uma vez que Internet e Tecnologia aparecem entre os mais representativos.

\section{Bolsas de Doutorado e Doutorado Direto (1993-2016)}

Em função da baixa representatividade das bolsas do Doutorado Direto, optamos por unir esta categoria ao Doutorado, cujos dados correspondem a 25 anos, entre 1992 e 2016, ao passo que o Doutorado Direto começou anos depois com registros de pesquisas apoiadas que vão de 2007 a 2016. A baixa procura pelo Doutorado Direto não é uma condição excepcional de fomento porque a sua adesão é praticamente na pós-graduação.

Por ter maior representatividade, começamos pelas pesquisas de Doutorado. As bolsas para este estágio da formação do pesquisador totalizam 68 e, dentro do montante de 583 bolsas de estudo concedidas no Brasil, sua representatividade é de 11,66\%. A USP, exclusivamente com a ECA, predomina com 43 pesquisas financiadas, o que representa 63,23\% das bolsas. Já no âmbito de instituição privada, está a PUC-SP, com 19 bolsas, e um índice de 27,94\%. Essas 68 bolsas estão integralmente em universidades sendo 47 (69,12\%) nas públicas e 21 (30,88\%) nas particulares, como ilustram os quadros a seguir.

Quadro 13 - Distribuição das 47 Bolsas de Doutorado em Universidades Públicas

\begin{tabular}{lll}
\hline INSTITUIÇÃO & NÚMERO DE BOLSAS & ÍNDICE PERCENTUAL \\
\hline USP & 43 & $91,49 \%$ \\
UNICAMP & 4 & $8,51 \%$ \\
\hline
\end{tabular}

Fonte: Biblioteca Virtual FAPESP.

Quadro 14 - Distribuição das 21 Bolsas de Doutorado em Universidades Particulares

\begin{tabular}{lll}
\hline INSTITUIÇÃO & NÚMERO DE BOLSAS & ÍNDICE PERCENTUAL \\
\hline PUC-SP & 19 & $90,48 \%$ \\
METODISTA S.PAULO & 2 & $9,52 \%$ \\
\hline
\end{tabular}

Fonte: Biblioteca Virtual FAPESP. 
Os pesquisadores contemplados com essas bolsas estão em São Paulo, São Bernardo do Campo e Campinas, sendo a capital paulista a mais beneficiada pela concessão dos fomentos.

Quadro 15 - Localidade das Pesquisas com Bolsas de Doutorado no Estado

\begin{tabular}{lll}
\hline LOCALIZAÇÃO GEOGRÁFICA & NÚMERO DE BOLSAS & ÍNDICE PERCENTUAL \\
\hline S.PAULO - CAPITAL & 62 & $91,17 \%$ \\
S.PAULO - INTERIOR & 4 & $5,88 \%$ \\
GRANDE SP (ABC) & 2 & $2,95 \%$ \\
\hline
\end{tabular}

Fonte: Biblioteca Virtual FAPESP.

Para todas essas bolsas, existem 38 mulheres (55,88\%) responsáveis pela orientação das pesquisas, enquanto os homens são 30 (44,12\%). A pesquisadora responsável com mais bolsas contempladas foi Lúcia Santaella, com um total de nove. Entre os orientandos, os números mostram que, entre 1992 e 2016, no Doutorado, foram 39 orientandas (57,35\%) e 29 orientandos (42,65\%). Dessas 68 bolsas, excluem-se 14 que não mencionaram seus temas e trabalhos com os beneficiados que informaram, em 54 pesquisas $(79,41 \%), 125$ temas. Os mais representativos foram considerados a partir de 1,5\% de representatividade.

Quadro 16 - Temas de Pesquisa no Doutorado

\begin{tabular}{lll}
\hline TEMAS & NÚMERO DE MENÇÕES & ÍNDICE PERCENTUAL \\
\hline Comunicação Organizacional & 3 & $2,4 \%$ \\
Jornalismo & 3 & $2,4 \%$ \\
Interatividade & 2 & $1,6 \%$ \\
Internet & 2 & $1,6 \%$ \\
Mídia Digital & 2 & $1,6 \%$ \\
Artes & 2 & $1,6 \%$ \\
Contemporaneidade & 2 & $1,6 \%$ \\
Moda & 2 & $1,6 \%$ \\
Design & 2 & $1,6 \%$ \\
Relações Públicas & 2 & $1,6 \%$ \\
Identidade Cultural & 2 & $1,6 \%$ \\
Indústria Cultural & 2 & $1,6 \%$ \\
Televisão & 2 & $1,6 \%$ \\
\hline
\end{tabular}

Fonte: Biblioteca Virtual FAPESP.

Na análise do uso das metodologias, das 68 bolsas concedidas pela FAPESP, 46 (67,65\%) não tiveram referência alguma à adoção metodológica, enquanto a minoria, isto é, 
em 22 bolsas (32,35\%), tal informação foi prestada sendo sua representatividade considerada acima de $5 \%$.

Quadro 17 - Metodologias de Pesquisa no Doutorado

\begin{tabular}{lll}
\hline TIPO DE METODOLOGIA & NÚMERO DE MENÇÕES & ÍNDICE PERCENTUAL \\
\hline Pesquisa Bibliográfica & 7 & $31,81 \%$ \\
Pesquisa Documental & 4 & $18,18 \%$ \\
Entrevista & 2 & $9,09 \%$ \\
Semiótica da Cultura & 2 & $9,09 \%$ \\
Estudo de Caso & 2 & $9,09 \%$ \\
Pesquisa de Observação & 2 & $9,09 \%$ \\
\hline
\end{tabular}

Fonte: Biblioteca Virtual FAPESP.

Outro dado importante, que faz parte da nossa análise e não é muito informado, é a Bibliografia. Nas 68 bolsas apoiadas pela FAPESP, 44 (64,7\%) não trazem essa informação, importante para sinalizar o percurso teórico no qual a pesquisa se sustenta. Em 24 pesquisas (35,3\%), constam autores e os mais citados, considerando margem superior a 5\%, se encontram a seguir.

Quadro 18 - Referências adotadas nas Pesquisas de Doutorado

\begin{tabular}{lll}
\hline AUTOR & NÚMERO DE PESQUISAS & ÍNDICE PERCENTUAL \\
\hline Charles S. Peirce & 5 & $20,83 \%$ \\
Michel Foucault & 2 & $8,33 \%$ \\
Vladimir Propp & 2 & $8,33 \%$ \\
Arlindo Machado & 2 & $8,33 \%$ \\
\hline
\end{tabular}

Fonte: Biblioteca Virtual FAPESP.

Nas referências bibliográficas, estão listados 69 autores, distribuídos de acordo com suas nacionalidades no quadro a seguir:

Quadro 19 - Nacionalidade dos autores referenciados em Doutorado

\begin{tabular}{lll}
\hline NACIONALIDADE & AUTORES & ÍNDICE PERCENTUAL \\
\hline Estrangeiros & 55 & $79,71 \%$ \\
Brasileiros & 11 & $15,94 \%$ \\
Não identificada & 3 & $4,35 \%$ \\
\hline
\end{tabular}

Fonte: Biblioteca Virtual FAPESP. 
Conforme mencionado, em função da pouca representatividade e por se tratar de uma modalidade de fomento pouco expressiva, o Doutorado Direto aparece, entre 583 bolsas, com apenas duas (0,34\%). Somente a ECA/USP aparece como beneficiária, o que obviamente se torna um fomento exclusivo e $100 \%$ da capital também com o mesmo índice na conjuntura da universidade pública. São dois pesquisadores responsáveis: Ivan Prado Teixeira e Waldomiro de Castro Santos Vergueiro. O mesmo acontece com os beneficiários, no caso, os pesquisadores Celbi Vagner Melo Pegoraro e Thiago Mio Salla. Uma bolsa tem tema informado, a outra não. A que aparece, traz como histórico da pesquisa a História em Quadrinhos, a Animação e a Produção Artística. Nenhuma delas informa metodologia e autores de referência.

É por isso que se nota a inviabilidade do Doutorado Direto, que perpassa uma etapa importante de contato com a vida acadêmica, o Mestrado. Já em relação ao Doutorado tradicional, é possível afirmar inicialmente que há maior preocupação com as atuais tendências de processos ligados à Revolução Digital, quando aparecem temáticas como Internet e Mídia Digital. Em comparação à Iniciação Científica e ao Mestrado, mesmo tendo menos pesquisas financiadas, percebe-se menor fragmentação temática, como ocorria com o Jornalismo e a Comunicação, e uma maior participação das disciplinas que formam a Área da Comunicação. Em termos metodológicos, predomina a Pesquisa Bibliográfica. Assim como vem sendo recorrente, a literatura estrangeira predomina, com alguns autores latinos em meio a uma concentração europeia.

\section{Bolsas de Pós-Doutorado (1998-2016)}

Em 18 anos de bolsas concedidas, essa fase de amadurecimento do pesquisador representa tímidos 6,18\% dos fomentos, em um universo de 583 pesquisas apoiadas, ou seja, são 36 bolsas financiadas. A USP detém o maior número (19), seguida por PUC-SP, com 13, UFSCAR e UNICAMP, com duas cada. Todas as bolsas estão em universidades sendo 63,88\% públicas e 36,12\% particulares, no caso, exclusivamente, a PUC-SP.

Quadro 20 - Distribuição das 38 Bolsas de Pós-Doutorado

\begin{tabular}{lll}
\hline INSTITUIÇÃO & NÚMERO DE BOLSAS & ÍNDICE PERCENTUAL \\
\hline USP & 19 & $52,78 \%$ \\
PUC-SP & 13 & $36,12 \%$ \\
UFSCAR & 2 & $5,55 \%$ \\
UNICAMP & 2 & $5,55 \%$ \\
\hline
\end{tabular}

Fonte: Biblioteca Virtual FAPESP.

As bolsas de Pós-Doutorado foram concedidas para pesquisadores que estão em São Paulo, São Carlos e Campinas. Das 36 bolsas, 32 ficaram na capital $(88,89 \%)$ e quatro 
(11,11\%) no interior. Elas foram concedidas a 19 mulheres (52,78\%) e 17 homens (47,22\%). O pesquisador com mais bolsas recebidas na condição de supervisor foi Ciro Juvenal Rodrigues Marcondes Filho, da ECA/USP, com quatro supervisões.

Entre esses pesquisadores bolsistas, cinco (13,89\%) não informaram os temas de pesquisa, situação feita por 31 desses pesquisadores (86,11\%). No total, foram 69 temas. Considerada a margem superior a 1,5\%, temos, em primeiro, a Censura (4,34\%), mencionada três vezes, seguida pela Divulgação Científica (2,89\%), mencionada duas vezes. Quando são consideradas as metodologias, a maioria das pesquisas - 23 (63,89\%) - também prestou informação, enquanto isso não ocorreu em 13 pesquisas (36,11\%). As metodologias foram citadas 38 vezes e as mais representativas são as superiores a 5\% na média.

Quadro 21 - Metodologias de Pós-Doutorado

\begin{tabular}{lll}
\hline TIPO DE METODOLOGIA & NÚMERO DE MENÇÕES & ÍNDICE PERCENTUAL \\
\hline Pesquisa Documental & 8 & $21,05 \%$ \\
Estudo de Caso & 4 & $10,52 \%$ \\
Análise Fílmica & 2 & $5,26 \%$ \\
Estudo Comparado & 2 & $5,26 \%$ \\
Pesquisa Bibliográfica & 2 & $5,26 \%$ \\
Pesquisa de Observação & 2 & $5,26 \%$ \\
\hline
\end{tabular}

Fonte: Biblioteca Virtual FAPESP.

Quando o assunto é Bibliografia, das 36 bolsas do Pós-Doutorado, 21 (58,33\%) não mencionam autores utilizados, sendo esta informação presente apenas em 15 pesquisas (41,67\%). Elas produziram 41 referências que podem aparecer em mais de uma pesquisa. Considerada a margem superior de 2,5\%, os autores mais representativos são Villém Flusser (três citações - 7,35\%) e Hans Belting, J.Greimas, Marshall McLuhan, Eric Landowski e Walter Benjamin, todos com duas citações cada e referencial de 4,87\%. Todos os autores citados chegam a 34 nomes e a divisão, por nacionalidade, se encontra no quadro que segue.

Quadro 22 - Nacionalidade dos autores referenciados em Pós-Doutorado

\begin{tabular}{lll}
\hline NACIONALIDADE & AUTORES & ÍNDICE PERCENTUAL \\
\hline Estrangeiros & 30 & $88,24 \%$ \\
Brasileiros & 4 & $11,76 \%$ \\
\hline
\end{tabular}

Fonte: Biblioteca Virtual FAPESP.

Verifica-se no estrato de dados, especialmente em relação aos temas, a interdisciplinaridade com outras Áreas do Conhecimento como Neurociências, Psicanálise e Psicologia; a fragmentação do tema Comunicação e temas mais cotidianos que abordam 
diretamente o aspecto comum da vida das sociedades. Embora quando passamos ao que seja mais representativo haja duas frentes de trabalho apenas: a censura e a divulgação cientifica. Em relação às metodologias, há uma tipificação maior, com destaque para a Pesquisa Documental. Na bibliografia, predomínio da literatura estrangeira, com forte influência dos pensadores europeus e autores que transitam pela interdisciplinaridade.

\section{Considerações Finais}

Do ponto de vista quantitativo, a produtividade analisada permite afirmar que a Comunicação segue atraindo novos pesquisadores, o que demonstra às instituições que os estudantes de Graduação também podem considerar a carreira de pesquisador a partir do curso escolhido.

Sobre o alcance do fomento, é patente que o maior engajamento está entre os estudantes de Universidades Públicas. Isto é positivo, por um lado, porque em tempos tão sombrios para a ciência brasileira, o interesse pela pesquisa acadêmica sobrevive; por outro, a grande quantidade de bolsas conseguidas pode sugerir "visão errônea" de que o fomento FAPESP seja algo estritamente governamental, voltado apenas ao ensino público. Aqui se coloca um desafio para as instituições privadas em conhecer mais sobre a possibilidade de pleitear o fomento. Para isso, há modelos referenciais como da PUC-SP, um dos Centros de Excelência que qualificamos na Área da Comunicação.

Por Centros de Excelência, consideramos as instituições com maior número de apoios e presença constante na obtenção de fomentos em nossa amostra. Além da PUC-SP (que percebeu positivamente essa possibilidade de incentivar seu corpo discente aos fomentos), ainda temos a USP (que se confunde com a história da própria FAPESP) e a UNESP Bauru (que se destaca na Iniciação Científica e no Mestrado), contribuindo para a formação de novas gerações de pesquisadores. Apesar do campus da UNESP, em Bauru, garantir essa força ao interior paulista, é ainda a capital São Paulo o destino de quem pretende estudar os temas da Comunicação de forma mais aprofundada. Porém, há de se mencionar o crescimento de São Carlos, com a UFSCAR, e de São Bernardo do Campo, com a Universidade Metodista, e sua tradição de 40 anos de pesquisas, completados em 2018. Tais tendências sinalizam para que as instituições do interior de São Paulo se arrojem no pedido de bolsas de estudo, principalmente do Doutorado em diante, para, assim, marcarem mais presença na Área promovendo a descentralização do grande centro.

Na relação orientador/orientando, enquanto os orientadores são predominantemente homens, entre os orientandos, quem mais conseguiu bolsas de estudo foram mulheres. Isto leva a uma possibilidade de inversão, pois, se elas estão pedindo mais bolsas, em nível de FAPESP, o cenário futuro projetado é que se tornem orientadoras em maior número.

Entre os temas de pesquisa, o Jornalismo predomina e isso tem uma justificativa: ele se confunde e se assimila à própria Comunicação, sendo, inclusive no nosso país, a primeira área de conhecimento na qual se obteve um doutoramento, com o trabalho do professor Luís 
Beltrão. Além disso, o Jornalismo foi a motivação inicial dos estudos ao longo da história da pesquisa em Comunicação, sendo ainda primordial para a institucionalização da Área.

Em relação às metodologias, a FAPESP necessita exigir mais em relação à informação de dados de pesquisa ou rever a alimentação de seu banco de dados, pois, algumas vezes, não constam menções a respeito da adoção metodológica de pesquisas que, entre todas as etapas de "Bolsas no Brasil”, se direcionam ao uso recorrente da Pesquisa Bibliográfica. Concomitantemente a esse assunto, o referencial bibliográfico com mais informações prestadas foi entre os pesquisadores do Mestrado. Ficou evidente que a Área ainda se vale da literatura estrangeira. O predomínio de produções de fora do Brasil é extenso e se faz em maior número entre os pesquisadores de Pós-Doutorado. Em contrapartida, o tipo de fomento em que se lê mais autores brasileiros é a Iniciação Científica, uma característica que faz sentido, já que a maioria de nossas produções se ocupa em debater a complexidade do campo, uma questão crucial de entendimento, debate e provocações para quem está ingressando na Área.

Do ponto de vista da Análise de Conteúdo, as implicações qualitativas surgem de algumas variáveis de inferência construídas a partir das Amostras. O Interesse pela Pesquisa em Comunicação se confirma quando Iniciação Científica e Mestrado apresentam grande demanda por bolsas. Na variável Universidade Pública, percebe-se que a exigência da Dedicação Exclusiva impede que muitos pesquisadores em formação consigam trabalhar concomitantemente aos estudos; a redução de investimentos governamentais tem atrapalhado o desempenho dessas instituições, questionadas em sua representatividade, em flagrante negação de nosso progresso como nação. Entre as Universidades e Faculdades Particulares, o fomento parece ter se tornado custeio do ensino.

O Objeto de Pesquisa carece de maior sistematização por conta da grande fragmentação que a Área vive em meio ao falso discurso de que tudo é ou possa vir a ser Comunicação. A Pesquisa Bibliográfica trata de recurso inerente, mas não o principal da pesquisa. Em relação à Interdisciplinaridade, é preciso entender os limites fronteiriços com a Área da Comunicação que preserva uma fragilidade sistêmica em se abrir a outros saberes sem priorizar suas raízes. E sobre Localização Geográfica, Capital e Interior, apesar de equiparados, se "separam” quando a cidade de São Paulo se confirma como grande centro de estudos em Comunicação.

Os resultados alcançados constituem um inventário do fluxo de produção de conhecimento para a própria FAPESP que, assim, pode visualizar o retorno dado pelos pesquisadores, em termos de conhecimento, ao dinheiro investido, sem que isto seja apenas por meio de relatórios burocráticos que comprovem o bom uso da verba pública. Pode-se dizer que, por trás do banco de dados da Biblioteca Virtual da FAPESP, existem tendências taxionômicas que dão representatividade às Ciências Sociais, uma vez que as pesquisas científicas são convalidadas pelo corpo técnico-científico da Fundação.

Sobre os desafios da Área da Comunicação, considerando como a FAPESP contribui, constrói e legitima a Comunicação, alguns apontamentos. A Contribuição está apontada, ao 
longo deste artigo, e denota como os pesquisadores exploram cientificamente seus objetos. Pela Legitimação, a Área tem forte representação institucional no Brasil, que, em contrapartida, não possui um pensamento comunicacional próprio. Parece-nos que o maior desafio para a Construção da Área é de âmbito pedagógico. Um bom começo, já revelado, é essa atração despertada pela Área entre os jovens que se inserem na pesquisa. Diante do excesso de Bibliografia Estrangeira, temos, nesse princípio, a chance de mostrar o potencial produtivo da Área. Avançar por este caminho evidencia que podemos trabalhar pedagogicamente um modelo conceitual à Comunicação para que ela tenha menos objetos fragmentados; conheça seus limites diante das outras Áreas; agregue mais pesquisadores natos em seu saber; iguale nossos pesquisadores e suas reflexões ao impacto teórico do exterior. Esse sentido epistemológico proposto poderia começar pelos Programas de Pós-Graduação revisitando suas produções ao longo do tempo.

\section{Referências}

BACHELARD, G. A formação do espírito científico: contribuição para uma psicanálise do conhecimento. Rio de Janeiro: Contraponto, 1996. 316p.

BACHELARD, G. Ensaio sobre o conhecimento aproximado. Tradução: Estela dos Santos Abreu. Rio de Janeiro: Contraponto, 2004. 318p.

BARDIN, L. Análise de conteúdo. Tradução: Luís Antero Reto, Augusto Pinheiro. São Paulo: Edições 70, 2011.

BIBLIOTECA Virtual da FAPESP - fonte referencial de informação para a pesquisa apoiada pela FAPESP. Fundação de Amparo à Pesquisa do Estado de São Paulo. São Paulo, 2004. Base de dados. Disponível em: http://www.bv.fapesp.br/pt/. Acesso em: 27 mar. 2016.

CAMPOS, M. L.; GOMES, H. E. Taxonomia e classificação: a categorização como princípio. Encontro Nacional de Pesquisa em Ciência da Informação (ENANCIB). Edição 2007. Disponível em: https:// enancib.ibict.br/index.php/enancib/viiienancib. Acesso em: 3 fev. 2018.

CONCESSÕES PARA BOLSAS E AUXÍLIOS À PESQUISA - 2017. FAPESP. Fundação de Amparo à Pesquisa do Estado de São Paulo. São Paulo. Disponível em: http://www.fapesp.br/10841. Acesso em: 3 fev. 2018.

DILTHEY, W. A construção do mundo histórico nas ciências humanas. São Paulo: UNESP, 2010. Tradução: Marco Casanova. 346p.

GABRIOTI, R. A FAPESP e a ciência da comunicação: legitimação, contribuição e construção da área. 2018. 349 p. Tese (Doutorado em Comunicação Social) - Escola de Comunicação, Educação e Humanidades da Universidade Metodista de São Paulo, São Bernardo do Campo, 2018. Orientação de: José Marques de Melo.

GOBBI, M. C. Conquistas e Carências. In: LINS, C. E.; MARQUES DE MELO, J.; GOBBI, M. C.; MORAIS, O. J. (Orgs.). Ciências da comunicação no Brasil 50 anos: histórias para contar. São Paulo: Vanguarda do Pensamento Brasileiro. São Paulo: Fapesp, Intercom, Unesp, 2015. 198p.

HAMBURGER, E.: depoimento [out. 2017]. Entrevistador: Rodrigo Gabrioti. São Paulo: USP, 2017. Entrevista concedida para a Tese.

MOURA, M. A Prima Pobre das Ciências Sociais. Revista Pesquisa FAPESP. São Paulo: n. 201, p. 27-33, 2014. 
RELATÓRIO de Atividades 2016. Resiliência na crise. Fundação de Amparo à Pesquisa do Estado de São Paulo (Fapesp). São Paulo. Disponível em: http://www.fapesp.br/ publicacoes/relat2016.pdf. Acesso em: 7 out. 2017.

REVISTA PESQUISA FAPESP. São Paulo: FAPESP, ed. 68. set. 2011.

SANTAELLA, L. Questionário FAPESP - tese Prof. Marques de Melo [mensagem pessoal]. Mensagem recebida por lbraga@pucsp.br em 03 out.2017.

\section{Rodrigo Gabrioti}

Doutor em Comunicação pela Universidade Metodista de São Paulo. Vencedor do Prêmio Freitas Nobre 2019, da Intercom. Um dos coordenadores da DTI 1 - Epistemologia, Teoria e Metodologia da Comunicação, na Assibercom. Coordenador do curso de Jornalismo da ESAMC Sorocaba. E-mail: rgabrioti@hotmail.com.

Recebido em: 25.10.2018

Aprovado em: 11.12.2019 